\title{
Characteristics of health care related to mental health and substance use disorders among Community Health Centre clients in Ontario: a population-based cohort study
}

\author{
Richard G. Booth RN PhD, Lucie Richard MA, Lihua Li PhD, Salimah Z. Shariff PhD, \\ Jennifer Rayner PhD
}

Abstract

Background: Community Health Centre $(\mathrm{CHC})$ client populations with a history of mental illness or substance use disorders, or both, are not described well in the literature. We identified $\mathrm{CHC}$ clients in Ontario with a history of health care related to mental health or substance use disorders, or both, and describe their demographic characteristics, health system use and related health risks in comparison to other people in the province with similar diagnoses who did not use CHC services.

Methods: We conducted a population-based cohort study using provincial health administrative data among Ontario residents aged 21-105 years with a previously established medical history of a mental illness or substance use disorder, or both. We examined 3 groups: clients of $\mathrm{CHC}$ sites that serve at-risk priority populations (PPCHCs) who presented for care at a CHC between Apr. 1, 2014, and Mar. 31, 2015, clients of CHC sites that serve nonpriority populations (NPPCHCs) who presented for care at a CHC over the same period, and a community control group of patients with a history of health care use related to mental illness or substance use disorders, or both, in the 2 years before the index date who were not $\mathrm{CHC}$ clients. We used descriptive statistics and multivariable logistic regression to estimate the odds of psychiatric care and emergency department use within 1 year of the index date.

Results: Compared to the community control patients $(n=1673200)$, clients of PPCHCs $(n=6575)$ and NPPCHCs $(n=15208)$ were younger, experienced more residential instability and had an increased prevalence of medical comorbidities; they had higher odds of receiving care from a psychiatrist (adjusted odds ratio [OR] 1.26, 95\% confidence interval [Cl] 1.20-1.33, and 1.47, 95\% $\mathrm{Cl}$ 1.41-1.53, respectively) and visiting an emergency department (adjusted OR 1.15, 95\% Cl 1.10-1.20, and 1.13, 95\% Cl 1.09-1.17, respectively) in the 1-year follow-up period.

Interpretation: Ontario $\mathrm{CHC}$ clients with mental health or substance use disorders had medically complex needs and were intensive users of the health care system. Specific interventions should be developed to better serve this vulnerable population.

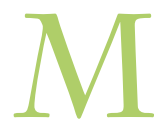

ental illness and substance use disorder are prevalent within the Ontario population, especially in vulnerable and marginalized populations. ${ }^{1,2}$ Owing to the ongoing stigma associated with these conditions, societal exclusion and isolation is commonplace, ${ }^{3,4}$ including within primary health care settings. ${ }^{5}$ In Ontario, Community Health Centres (CHCs) are a primary health care model that serves populations who experience barriers to obtaining health care (e.g., poverty, geographic isolation, ethno- and culturocentrism, racism, sexism, heterosexism, transphobia, language discrimination and other forms of social exclusion). ${ }^{6}$ Community Health Centres provide a comprehensive range of interprofessional health care services, including care from physicians, nurse practitioners, nurses, social workers, dieticians and health promoters. ${ }^{7}$ For over 40 years, CHCs have served over 600000 people in 110 communities across the province, ${ }^{8}$ including large populations of people living in lowerincome neighbourhoods with severe mental illness and chronic health conditions. ${ }^{9,10}$

Although mental illness and substance use disorders in Ontario have been studied, ${ }^{11,12}$ there is limited populationlevel research in this area specific to the $\mathrm{CHC}$ client population. Owing to the increasing rates of mental health problems and addictions in Ontario, ${ }^{1,13-15}$ obtaining a better understanding of $\mathrm{CHC}$ clients with a history of use of health care related

Competing interests: None declared.

This article has been peer reviewed.

Correspondence to: Richard Booth, rbooth5@uwo.ca

CMAJ Open 2020. DOI:10.9778/cmajo.20190089 
to mental illness or substance use disorder, or both, is needed, especially given that existing work has highlighted that $\mathrm{CHCs}$ serve populations with higher proportions of patients with complex medical and mental illnesses compared to the general Ontario population. ${ }^{9,10}$

The objectives of the present study were to identify $\mathrm{CHC}$ clients with a history of use of health care related to mental health or substance use disorder, or both, and describe their demographic characteristics, socioeconomic background, use of health care services and related health risks in comparison to community controls who did not use CHC services.

\section{Methods}

\section{Setting}

We conducted a population-based cohort study in Ontario, Canada using data from Apr. 1, 2014, to Mar. 31, 2015. We deemed this time span contemporary enough to be meaningful for practice and policy but with a sufficient lag to ensure completeness of health administrative data. Ontario has a single-payer health care insurance plan (Ontario Health Insurance Plan) that allows residents to access medically necessary health care services through providers and health care organizations. Records generated through interaction with the health care system thus represent the entire population.

\section{Data sources}

We identified $\mathrm{CHC}$ clients using the $\mathrm{CHC}$ data set, which was extracted from the $\mathrm{CHC}$ electronic medical record and linked deterministically to health administrative data sets housed at ICES. ${ }^{16}$ ICES is an independent, nonprofit research institute whose legal status under Ontario's health information privacy law allows it to collect and analyze health care and demographic data, without consent, for health system evaluation and improvement. We determined health care use using the Canadian Institute for Health Information Discharge Abstract Database (2011-2016), which contains patient-level hospital admission and discharges; the National Ambulatory Care Reporting System (2011-2016), which contains data related to ambulatory and emergency department use; the Ontario Mental Health Reporting System (20112016), which contains data related to all adults who receive mental health services; and the Ontario Health Insurance Plan (2011-2016) database, which contains physician billing and diagnostic data. In addition, we identified certain chronic conditions using ICES-derived data sets applying validated case definitions, including the Ontario Asthma data set, ${ }^{17}$ the Ontario Chronic Obstructive Pulmonary Disease cohort, ${ }^{18}$ the Ontario Diabetes data set, ${ }^{19}$ the Ontario Hypertension data set, ${ }^{20}$ the Ontario Rheumatoid Arthritis data set, ${ }^{21}$ the Ontario Crohn's and Colitis Cohort ${ }^{22}$ and the Ontario HIV database. $^{23}$

Other sociodemographic data used in the study were drawn from the ICES Registered Persons Database, the Immigration, Refugees and Citizenship Canada Permanent Residents data set (information on immigration), Client Agency Program Enrolment (patients registered to a primary health care physician), the Ontario Marginalization Index ${ }^{24,25}$ (levels of marginalization across the province, including the derived variables residential instability, material deprivation, dependency and ethnic concentration), and the Primary Care Population database ${ }^{26}$ (an ICES-derived population-level data set that contains a representative sample of Ontarians and their demographic and health information). These data sets were linked by means of unique encoded identifiers and analyzed at ICES.

\section{Study population}

The CHC group included all people aged 21-105 years who presented for care at a CHC between Apr. 1, 2014, and Mar. 31, 2015. We excluded those aged less than 21 years in order to provide a 3-year look-back window for specific comorbidities. All CHC clients in the study had a history of use of outpatient health care related to a mental health diagnosis or substance use, or both (Appendix 1, Supplemental Table S1, available at www.cmajopen.ca/content/8/2/E391/ suppl/DC1). We defined clients as having any health care interaction related to mental problems or substance use as indicated through outpatient (CHC or traditional physician visits), emergency department or inpatient diagnostic codes from the Discharge Abstract Database, the National Ambulatory Care Reporting System, the Ontario Mental Health Reporting System or the Ontario Health Insurance Plan database in the preceding 2-year period.

We categorized $\mathrm{CHC}$ clients into 2 subgroups, prioritypopulation $\mathrm{CHC}$ (PPCHC) clients and nonpriority-population $\mathrm{CHC}$ (NPPCHC) clients, using the $\mathrm{CHCV}$ variable within the $\mathrm{CHC}$ database. Priority-population $\mathrm{CHCs}$ are defined as $\mathrm{CHC}$ sites located in major urban environments that predominantly serve at-risk populations who are homeless or have challenges with mental health or substance addictions. ${ }^{16}$ There are currently 18 PPCHCs in Ontario. ${ }^{16}$ Nonpriority-population $\mathrm{CHCs}$ are all other $\mathrm{CHC}$ sites located in urban or rural areas of Ontario that serve populations with barriers to care (e.g., rural or remote, lack of ready access to other sources of primary health care) but have not been identified as priority populations in terms of homelessness or issues with mental health or substance addictions. ${ }^{16}$

As a comparator to the CHC client groups, we identified a reference population of people in Ontario aged 21-105 who had a history of health care use related to mental illness or substance use disorders, or both, in the 2 years before the index date and were not $\mathrm{CHC}$ clients during that period. This comparator population was drawn from the Primary Care Population database. ${ }^{26}$

\section{Outcome measures}

We assessed descriptively several outcomes occurring within 1 year after entry into the cohort to obtain an initial understanding of the CHC subgroups and their related health care use, including basic markers of quality of care (use of specialists and other health care services) and complexity of need (common chronic conditions, including asthma, chronic obstructive pulmonary disease, diabetes, hypertension, 
congestive heart failure or HIV infection). Selected outcomes included outpatient visits (whether to a primary health care physician or a CHC), visits to a subset of specialists (cardiologists, endocrinologists, psychiatrists or respirologists), emergency department visits and hospital admissions. We further investigated 2 previously reported outcomes indicative of quality of care for people with mental illness and addictions, with adjustment for potential confounders: receipt of psychiatrist care and an emergency department visit in the followup year. ${ }^{27}$

\section{Variables}

The exposure of interest was group type (PPCHC, NPPCHC or Ontario community control). We considered a range of other predictors, including age, sex, type of health care related to mental health or substance use disorders used within the previous 2 years and any past diagnosis of a chronic condition. Owing to the nature of the condition or issues related to data record completeness, other comorbidities were limited to diagnosis within the previous 3 years (chronic liver disease, chronic kidney disease, Crohn disease or ulcerative colitis, infective endocarditis or rheumatoid arthritis) or within 1 year of the index date (i.e., after entry into the cohort) (chronic pain, or skin or soft-tissue infection).

We used neighbourhood-level income quintiles and the Ontario Marginalization Index ${ }^{24,28}$ to show marginalization and area-level inequalities, using 2006 census data. We also identified whether people were rostered to a family physician at their cohort entry date, since, in Ontario, clients can be registered at a CHC and with another primary health care model simultaneously. ${ }^{9}$ Predictor and outcome variables, including standardized diagnosis and fee codes where applicable, are available in Appendix 1, Supplemental Table S1.

\section{Statistical analysis}

We compared baseline characteristics between groups using 1 -way analysis of variance and $\chi^{2}$ tests as appropriate. We then used 2 stratified multivariable logistic regressions to assess whether, after accounting for clustering by family physician, CHC client status was associated with 2 outcomes: receipt of health care from a psychiatrist and emergency department use within 1 year of the index date. We accounted for clustering of family physician at the index date using the STRATA statement in PROC LOGISTIC). We calculated adjusted odds ratios (ORs) with $95 \%$ confidence intervals (CIs). All analyses were conducted with SAS version 9.4 (SAS Institute).

\section{Ethics approval}

The use of data in this project was authorized under section 45 of Ontario's Personal Health Information Protection Act, which does not require review by a research ethics board.

\section{Results}

After exclusions, the cohort included $21783 \mathrm{CHC}$ clients (6575 PPCHC and $15208 \mathrm{NPPCHC}$ ) and 1673200 patients in the Ontario community control group with a history of health care related to a mental health or substance use disorder (Figure 1). The 3 subgroups had distinct demographic, comorbid and health care use profiles (Table 1, Figure 2). Clients of PPCHCs were generally younger than NPPCHC clients and community control patients. They had higher rates of health care use for psychotic disorders compared to NPPCHC clients and substantially more compared to community control patients. Clients of PPCHCs also had higher rates of health care use related to substance use disorder than

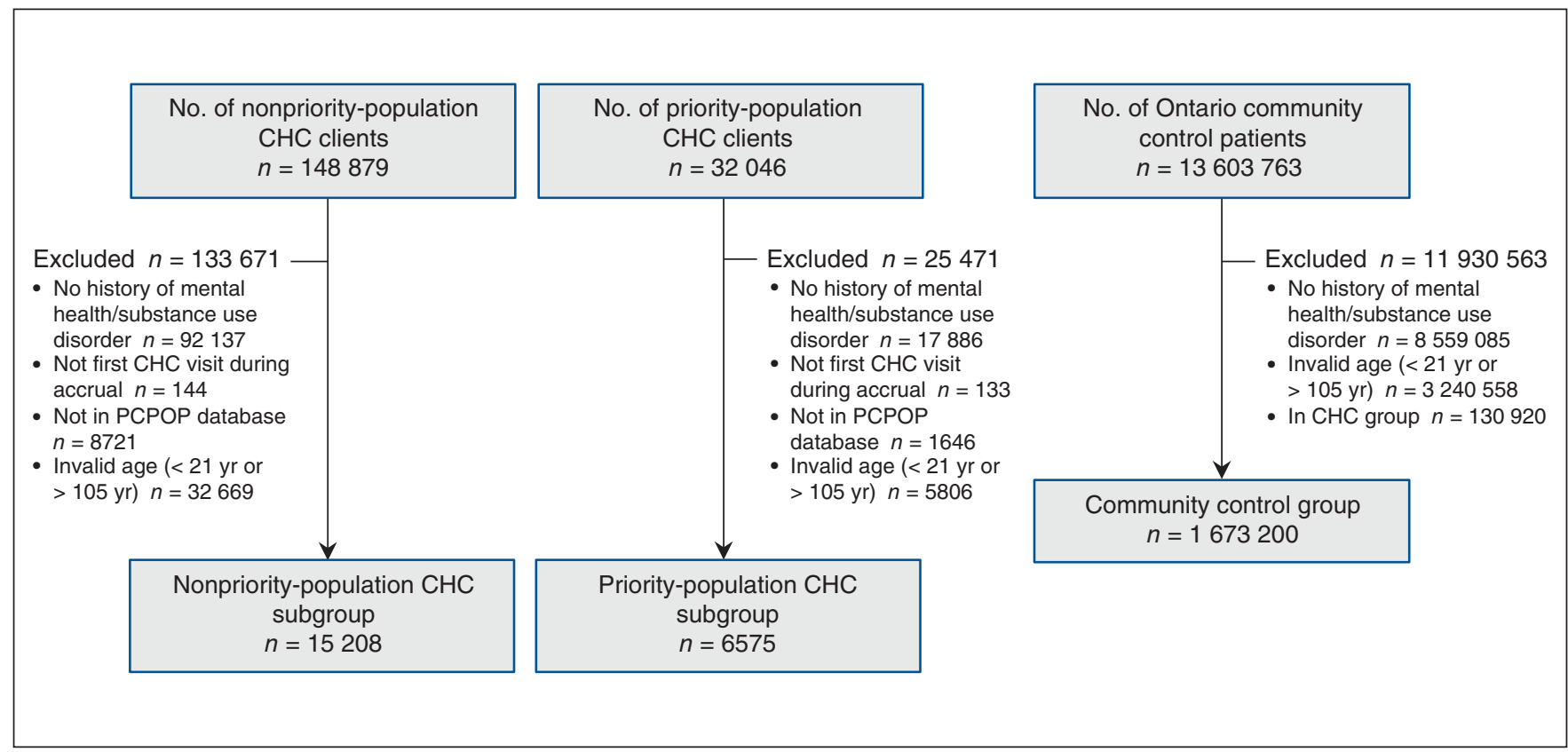

Figure 1: Flow diagram showing creation of the cohort subgroups. Note: $\mathrm{CHC}=$ Community Health Centre, PCPOP $=$ Primary Care Population. 
Table 1 (part 1 of 2): Characteristics of the cohort subgroups at baseline

\begin{tabular}{|c|c|c|c|}
\hline \multirow[b]{2}{*}{ Characteristic } & \multicolumn{3}{|c|}{ Group; no. (\%) of people* } \\
\hline & $\begin{array}{l}\text { Priority-population } \mathrm{CHC} \\
\qquad n=6575\end{array}$ & $\begin{array}{c}\text { Nonpriority-population } \\
\text { CHC } \\
n=15208\end{array}$ & $\begin{array}{c}\text { Community control } \\
n=1673200\end{array}$ \\
\hline Female sex & $3293(50.1)$ & $9050(59.5)$ & $978646(58.5)$ \\
\hline \multicolumn{4}{|l|}{ Age group, yr } \\
\hline $21-35$ & $1656(25.2)$ & $3712(24.4)$ & $361560(21.6)$ \\
\hline $35-49$ & $2240(34.1)$ & $4373(28.8)$ & $477381(28.5)$ \\
\hline $50-64$ & 2212 (33.6) & $5016(33.0)$ & $502974(30.1)$ \\
\hline$\geq 65$ & $467(7.1)$ & 2107 (13.9) & 331285 (19.8) \\
\hline \multicolumn{4}{|l|}{ Income quintile† } \\
\hline Quintile 1 (lowest) & $3030(46.1)$ & $6049(39.8)$ & 346854 (20.7) \\
\hline Quintile 2 & $1367(20.8)$ & $3258(21.4)$ & $330170(19.7)$ \\
\hline Quintile 3 & $961(14.6)$ & $2362(15.5)$ & 326318 (19.5) \\
\hline Quintile 4 & $687(10.4)$ & 1960 (12.9) & $340802(20.4)$ \\
\hline Quintile 5 (highest) & $448(6.8)$ & $1495(9.8)$ & $318302(19.0)$ \\
\hline \multicolumn{4}{|l|}{ Residential instability† } \\
\hline Quintile 1 (lowest) & 218 (3.3) & $1284(8.4)$ & 300967 (18.0) \\
\hline Quintile 2 & $373(5.7)$ & 1715 (11.3) & $293752(17.6)$ \\
\hline Quintile 3 & $611(9.3)$ & $2526(16.6)$ & 296501 (17.7) \\
\hline Quintile 4 & $1328(20.2)$ & $3528(23.2)$ & $325170(19.4)$ \\
\hline Quintile 5 (highest) & $3960(60.2)$ & $5980(39.3)$ & $443292(26.5)$ \\
\hline \multicolumn{4}{|l|}{ Material deprivation† } \\
\hline Quintile 1 (lowest) & $337(5.1)$ & $1278(8.4)$ & $278032(16.6)$ \\
\hline Quintile 2 & $494(7.5)$ & $1828(12.0)$ & $307538(18.4)$ \\
\hline Quintile 3 & 795 (12.1) & $2528(16.6)$ & $319847(19.1)$ \\
\hline Quintile 4 & $1354(20.6)$ & $2838(18.7)$ & $341218(20.4)$ \\
\hline Quintile 5 (highest) & $3510(53.4)$ & $6561(43.1)$ & $413047(24.7)$ \\
\hline \multicolumn{4}{|l|}{ Dependency† } \\
\hline Quintile 1 (lowest) & $1533(23.3)$ & $2890(19.0)$ & $416126(24.9)$ \\
\hline Quintile 2 & 1477 (22.5) & $2660(17.5)$ & 325971 (19.5) \\
\hline Quintile 3 & $1250(19.0)$ & $2878(18.9)$ & 299413 (17.9) \\
\hline Quintile 4 & 1069 (16.3) & $3068(20.2)$ & $283751(17.0)$ \\
\hline Quintile 5 (highest) & $1161(17.7)$ & 3537 (23.3) & $334421(20)$ \\
\hline \multicolumn{4}{|l|}{ Ethnic concentration† } \\
\hline Quintile 1 (lowest) & $1101(16.7)$ & $4076(26.8)$ & $257281(15.4)$ \\
\hline Quintile 2 & $1227(18.7)$ & $2679(17.6)$ & $285263(17.0)$ \\
\hline Quintile 3 & $1089(16.6)$ & $2032(13.4)$ & 320477 (19.2) \\
\hline Quintile 4 & $1727(26.3)$ & $3034(20.0)$ & 366559 (21.9) \\
\hline Quintile 5 (highest) & $1346(20.5)$ & $3212(21.1)$ & $430102(25.7)$ \\
\hline Recent immigrant status $\ddagger$ & $148(2.3)$ & $560(3.7)$ & 65024 (3.9) \\
\hline Rural residence§ & 214 (3.3) & 2958 (19.5) & $164704(9.8)$ \\
\hline Rostered to family physician & 2029 (30.9) & 4467 (29.4) & 1368951 (81.8) \\
\hline
\end{tabular}


Table 1 (part 2 of 2): Characteristics of the cohort subgroups at baseline

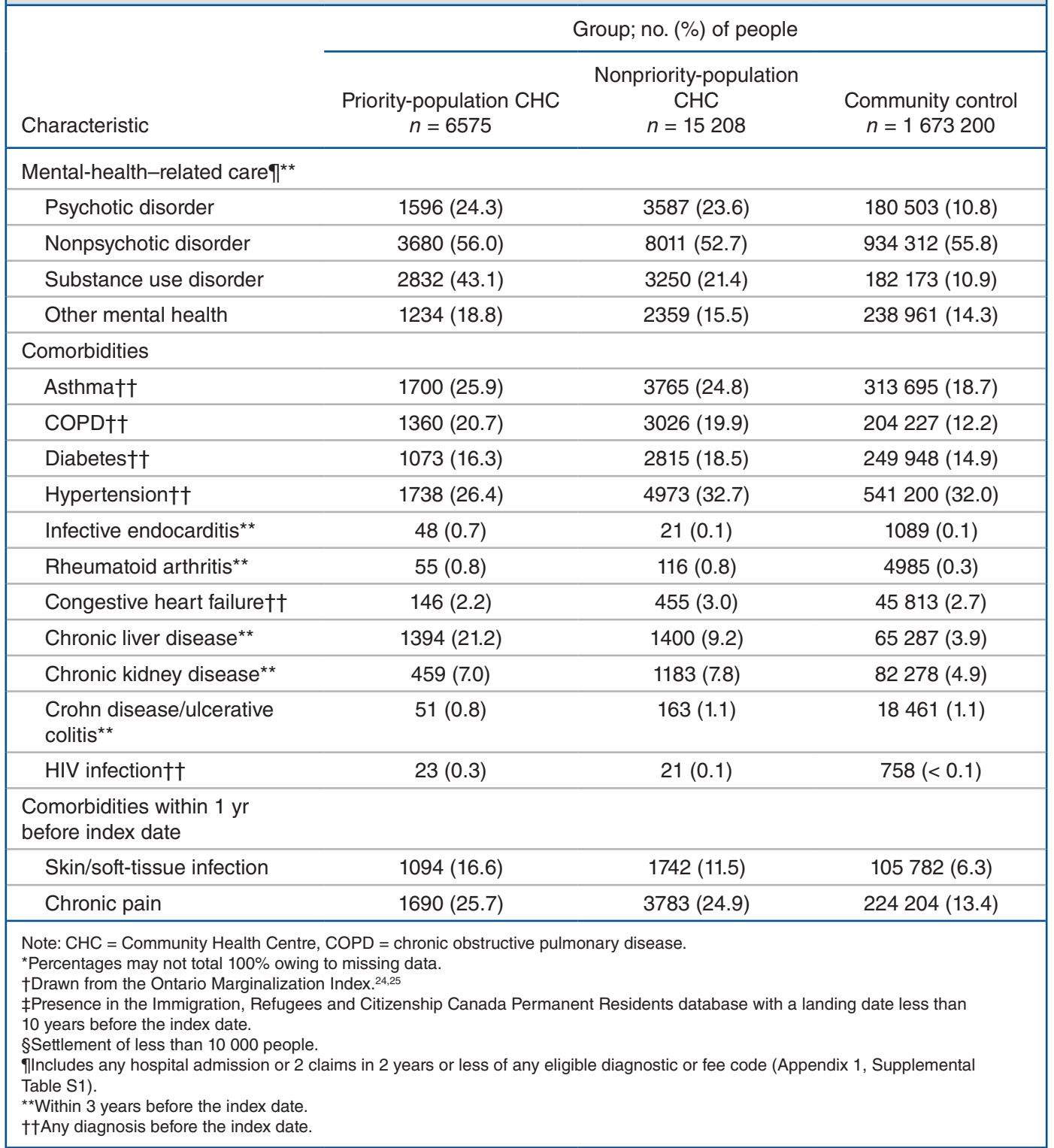

NPPCHC clients and community control patients. In addition, clients of PPCHCs had higher rates of chronic liver disease and skin and soft-tissue infections than NPPCHC clients and community control patients.

Figure 3 illustrates the differences between the subgroups across elements of the Ontario Marginalization Index. ${ }^{24,25}$ More PPCHC clients resided in areas of lower income and greater material deprivation, residential instability and dependency compared to NPCHC clients and community control patients.

Clients of NPPCHCs were more likely to live in rural areas and have middle incomes, and less likely to be rostered to a primary health care physician practice than PPCHC clients and especially community control patients. The 3 groups had similar rates of health care use for nonpsychotic disorders. Clients of NPPCHCs and community control patients had similar rates of congestive heart failure, hypertension, and Crohn disease or ulcerative colitis, which were higher than those observed for PPCHC clients.

One-year unadjusted outcomes are presented in Table 2. Overall, PPCHC clients had higher rates of outpatient primary health care visits and emergency department visits than NPPCHC clients and community control patients. The proportions of PPCHC and NPPCHC clients who had psychiatrist and respirologist visits were similar and were higher than the proportion of community control patients with such visits. Clients of NPPCHCs had a higher proportion of visits to endocrinologists than did PPCHC clients and community control patients.

The odds of a PPCHC client's receiving care from a psychiatrist or visiting an emergency department in the year after 


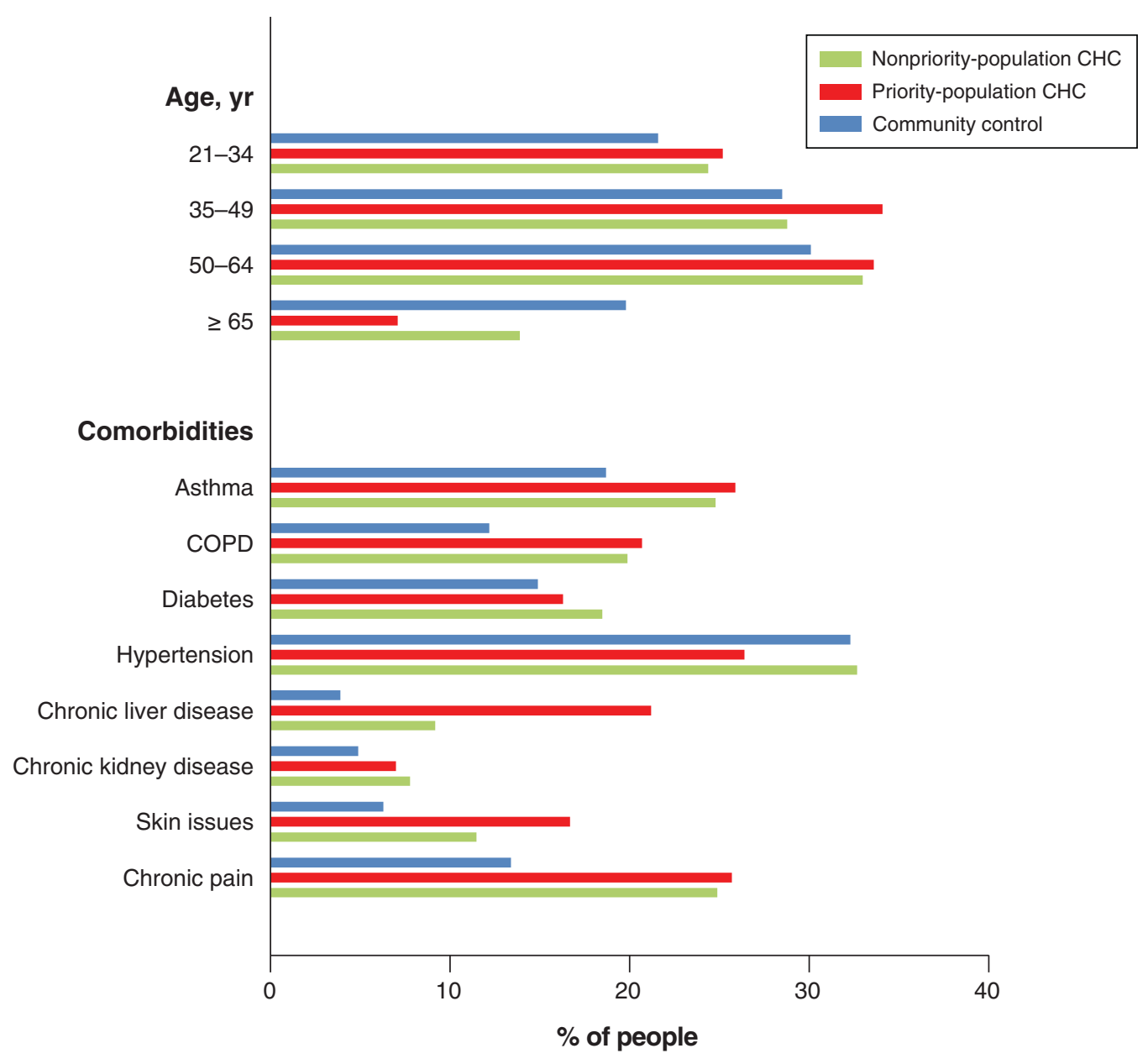

Figure 2: Selected demographic and comorbidity characteristics of the cohort subgroups at baseline. Note: $\mathrm{CHC}=\mathrm{Community} \mathrm{Health}$ Centre, COPD = chronic obstructive pulmonary disease.

interaction with a CHC was $26 \%$ (adjusted OR $1.26,95 \%$ CI $1.20-1.33$ ) and $15 \%$ (adjusted OR 1.15, 95\% CI 1.10-1.20) higher, respectively, compared to community control patients (Table 3). The corresponding odds for NPPCHC clients was $47 \%$ (adjusted OR $1.47,95 \%$ CI $1.41-1.53$ ) and $13 \%$ (adjusted OR 1.13, 95\% CI 1.09-1.17) higher.

\section{Interpretation}

In this population-based study set in Ontario, we examined characteristics and health care use of a cohort of people with a history of health care related to mental health or substance use disorders seen at PPCHCs and NPPCHCs. It appears that both PPCHC and NPPCHC clients had higher rates of mental health conditions or substance use disorder, or both, than a reference population of people who had a history of health care use related to mental health or substance use disorders in the preceding 2 years who were not $\mathrm{CHC}$ clients during that period. Furthermore, PPCHC and NPPCHC clients were generally younger and poorer, and had increased levels of material deprivation, residential instability and comorbidity complexity compared to the Ontario population. Not surprisingly, both PPCHC clients and NPPCHC clients were also more intensive users of clinical specialists, emergency departments and hospitals. Taken together, these findings suggest that $\mathrm{CHC}$ clients with a history of health care related to mental health or substance use disorders likely have more complex medical needs and are more vulnerable than the average Ontarian with such a disorder. These findings, in conjunction with the reported descriptive statistics, highlight the complex needs of both PPCHC and NPPCHC clients who have health care use related to mental health problems or substance use disorder.

The striking differences in the clinical needs of $\mathrm{CHC}$ clients compared to a representative Ontario population are consistent with other research in this area.9,16 Previous research exploring residential instability has suggested that lack of stable housing can influence health status in major ways. ${ }^{29-31}$ For instance, PPCHC clients in our study appeared to be younger and to have higher rates of residential instability 


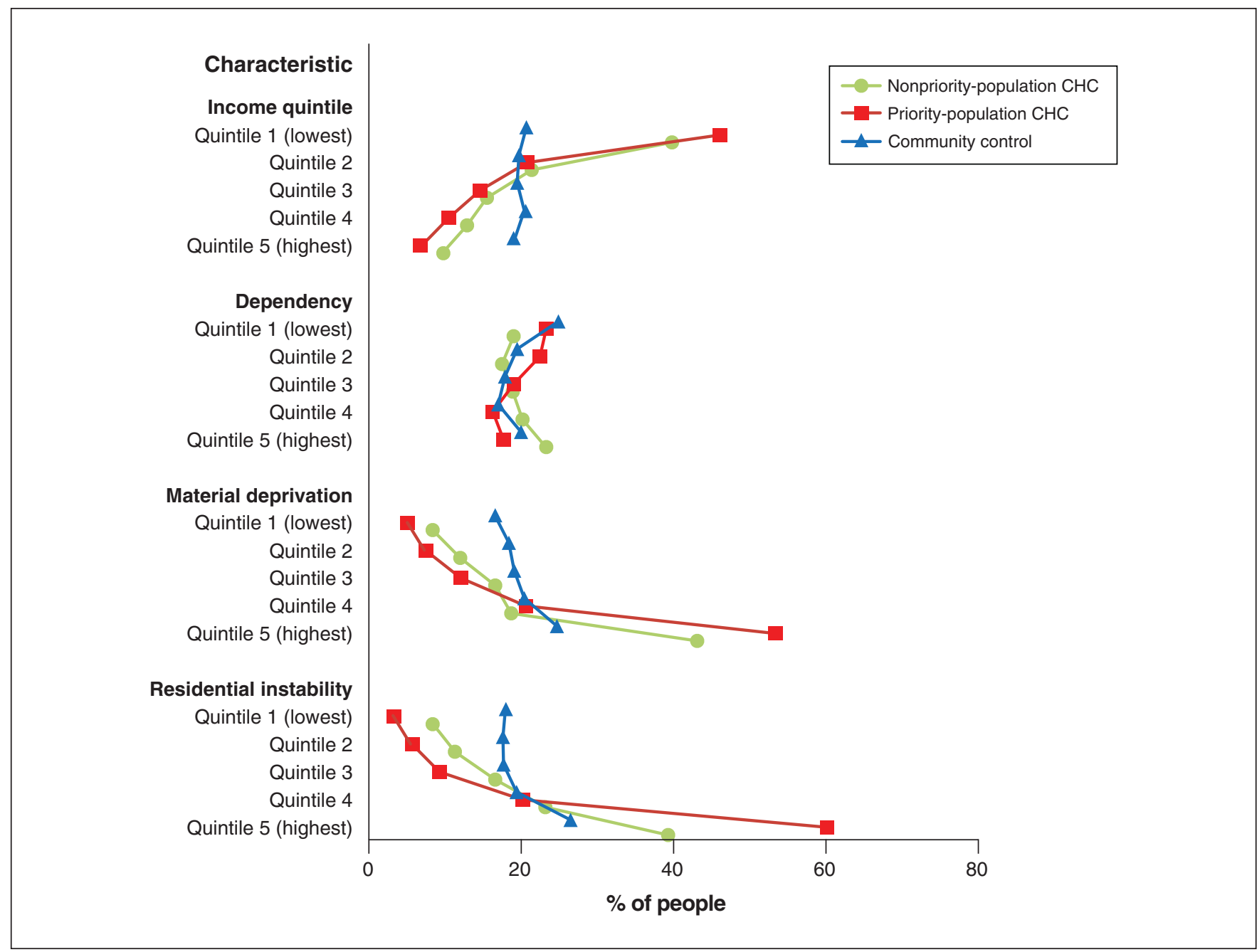

Figure 3: Ontario Marginalization Index ${ }^{24,25}$ characteristics of the cohort subgroups at baseline. Note: $\mathrm{CHC}=\mathrm{Community} \mathrm{Health} \mathrm{Centre}$.

\begin{tabular}{|c|c|c|c|}
\hline \multirow[b]{2}{*}{ Outcome } & \multicolumn{3}{|c|}{ No. (\%) of people* } \\
\hline & $\begin{array}{c}\text { Priority-population } \\
\text { CHC } \\
n=6575\end{array}$ & $\begin{array}{c}\text { Nonpriority-population } \\
\text { CHC } \\
n=15208\end{array}$ & $\begin{array}{c}\text { Community control } \\
n=1673200\end{array}$ \\
\hline \multicolumn{4}{|l|}{ Specialist visit } \\
\hline Psychiatrist & $2514(38.2)$ & $5891(38.7)$ & 265417 (15.9) \\
\hline Respirologist & $624(9.5)$ & $1399(9.2)$ & $67295(4.0)$ \\
\hline Endocrinologist & $270(4.1)$ & $1016(6.7)$ & 60415 (3.6) \\
\hline Cardiologist & $2262(34.4)$ & $3750(24.7)$ & $117933(7.0)$ \\
\hline $\begin{array}{l}\text { Primary health care visit, rate per } \\
1000 \text { patients }(95 \% \mathrm{Cl})\end{array}$ & $34.41(34.27-34.55)$ & $25.53(25.45-25.61)$ & $16.30(16.29-16.30)$ \\
\hline $\begin{array}{l}\text { Emergency department visit, rate } \\
\text { per } 1000 \text { patients }(95 \% \mathrm{Cl})\end{array}$ & $2.55(2.51-2.58)$ & $1.50(1.48-1.52)$ & $0.71(0.71-0.71)$ \\
\hline $\begin{array}{l}\text { Hospital admission, rate per } \\
1000 \text { patients }(95 \% \mathrm{Cl})\end{array}$ & $0.26(0.25-0.28)$ & $0.20(0.19-0.21)$ & $0.13(0.13-0.13)$ \\
\hline
\end{tabular}




\begin{tabular}{|c|c|c|}
\hline Outcome; group & $\begin{array}{l}\text { Unadjusted OR } \\
\qquad(95 \% \mathrm{Cl})\end{array}$ & $\begin{array}{l}\text { Adjusted OR } \\
\quad(95 \% \mathrm{Cl})\end{array}$ \\
\hline \multicolumn{3}{|l|}{ Psychiatric care* } \\
\hline Community control & 1.00 (referent) & 1.00 (referent) \\
\hline Priority-population $\mathrm{CHC}$ & 1.47 (1.42-1.52) & $1.26(1.20-1.33)$ \\
\hline $\begin{array}{l}\text { Nonpriority-population } \\
\mathrm{CHC}\end{array}$ & $1.50(1.46-1.54)$ & $1.47(1.41-1.53)$ \\
\hline \multicolumn{3}{|l|}{$\begin{array}{l}\text { Emergency department } \\
\text { use† }\end{array}$} \\
\hline Community control & 1.00 (referent) & 1.00 (referent) \\
\hline Priority-population $\mathrm{CHC}$ & $1.52(1.47-1.58)$ & $1.15(1.10-1.20)$ \\
\hline $\begin{array}{l}\text { Nonpriority-population } \\
\mathrm{CHC}\end{array}$ & $1.13(1.10-1.16)$ & $1.13(1.09-1.17)$ \\
\hline \multicolumn{3}{|c|}{$\begin{array}{l}\text { Note: } \mathrm{CHC}=\text { Community Health Centre, } \mathrm{Cl}=\text { confidence interval, OR = odds ratio. } \\
\text { *Variables adjusted for: age, sex, income quintile, residential instability, material } \\
\text { deprivation, dependency, ethnic concentration, recent immigrant status, rural } \\
\text { residence, mental-health-related health care, CHC use in prior } 3 \text { years, rostered } \\
\text { to family physician at index date (we accounted for clustering of family physician at } \\
\text { index date using the STRATA statement in PROC LOGISTIC). } \\
\text { †Variables adjusted for: as above, and comorbidities in prior } 3 \text { years (i.e., chronic } \\
\text { liver disease, chronic kidney disease, Crohn disease or ulcerative colitis, } \\
\text { rheumatoid arthritis, infective endocarditis), any diagnosis of comorbidity before } \\
\text { index date (i.e., asthma, chronic obstructive pulmonary disease, diabetes, } \\
\text { hypertension, congestive heart failure, HIV infection), comorbidities in prior year } \\
\text { (i.e., skin or soft-tissue infection, chronic pain). }\end{array}$} \\
\hline
\end{tabular}

and material deprivation than NPPCHC clients and especially community control patients. Consistent with other research examining community-based vulnerable populations, we found that, compared to the control group, CHC clients were more likely to use emergency department resources, ${ }^{1,32}$ obtain specialist health care services ${ }^{29}$ and have high levels of medical comorbidities, ${ }^{33}$ and less likely to be rostered to a family physician..$^{33}$ Given the higher levels of residential instability and use of health care resources among PPCHC and NPPCHC clients, appropriate housing services and models of care that can support the complex needs of these clients should be developed.

As a cohort of the Ontarian population that does not appear to be well rostered to traditional physician-based primary health care services, $\mathrm{CHC}$ clients may have been underrepresented in previous population-level examinations of use of primary health care based on health administrative data in Ontario. Our analysis using the CHC database, a relatively recent addition to ICES, ${ }^{16}$ suggests that clients of both PPCHCs and NPPCHCs have more complex medical needs and higher levels of material deprivation and residential instability than a comparable Ontario population. Further work is required to better describe $\mathrm{CHC}$ clients with mental health or substance use disorders and their larger patterns of health care use across the system.

It appears that the majority of $\mathrm{CHC}$ clients with mental health or substance use issues relied heavily on CHCs as their primary avenue for primary health care services. This finding, along with the complex health care needs of this vulnerable population, has important policy and practice implications for database research: $\mathrm{CHC}$ clients must be represented adequately in future primary health care research based on population-level data.

\section{Limitations}

Although it would have been possible to examine people with either a mental health disorder or a substance use disorder, given the high prevalence of the concurrent diagnosis of the 2 disorders among clients of PPCHCs and NPPCHCs, we collapsed the 2 potential groups into 1 group. Further work is required to examine subsets of the CHC population and to quantify the current burden of co-occurring mental health and substance use disorders on people's lives and the health care system.

This study is also subject to numerous confounders present in society. Although we accounted for various relevant covariates (e.g., material derivation, elements of multimorbidity, past interaction with the health care system), drawing causal inferences from this study should be avoided. In addition, because of differences in the inclusion criteria for the CHC groups and the community control group, there may be important differences between the CHC groups and the community control group. Finally, given that our study was based on health administrative data, we were unable to account for a range of variables that are determinants of health, including housing, education, and other social and physical environmental factors that can influence health substantially. ${ }^{34}$

\section{Conclusion}

Ontario CHC clients with a diagnosis of mental health problems or substance use disorders, or both, had patterns of health system use that were noticeably different from those of other people in the province with similar diagnoses. As intensive users of health care resources, CHC clients with health care use related to mental health or substance use disorders need to be studied further so that more specific interventions can be developed to better serve this vulnerable population.

\section{References}

1. Hensel JM, Taylor VH, Fung K, et al. Rates of mental illness and addiction among high-cost users of medical services in Ontario. Can f Psychiatry 2016;61: 358-66.

2. Hensel JM, Taylor VH, Fung K, et al. Unique characteristics of high-cost users of medical care with comorbid mental illness or addiction in a population-based cohort. Psychosomatics 2018;59:135-43.

3. Patten SB, Williams JVA, Lavorato DH, et al. Perceived stigma among recipients of mental health care in the general Canadian population. Can 7 Psychiatry 2016;61:480-8.

4. Knaak S, Mantler E, Szeto A. Mental illness-related stigma in healthcare: barriers to access and care and evidence-based solutions. Healthc Manage Forum 2017;30:111-6.

5. Ross LE, Vigod S, Wishart J, et al. Barriers and facilitators to primary care for people with mental health and/or substance use issues: a qualitative study. $B M C$ Fam Pract 2015;16:135.

6. CHC fact sheet. Toronto: Alliance for Healthier Communities; 2018. Available: https://www.allianceon.org/chc-fact-sheet (accessed 2020 Jan. 16).

7. Rayner J, Muldoon L. Staff perceptions of Community Health Centre team function in Ontario. Can Fam Physician 2017;63:e335-40.

8. Rayner J, Muldoon L, Bayoumi I, et al. Delivering primary health care as envisioned: a model of health and well-being guiding community-governed primary care organizations. F Integr Care (Brighton) 2018;26:231-41. 
9. Glaizer R, Zagorski B, Rayner J. Comparison of primary care models in Ontario by demographics, case mix and emergency department use, 2008/09 to 2009/10. ICES investigative report. Toronto: ICES; 2012.

10. Khenti A, Thomas F, Mohamoud S, et al. Mental health and addictions capacity building for Community Health Centres in Ontario. Can Fam Physician 2017;63:e416-24

11. Gomes T, Khuu W, Martins D, et al. Contributions of prescribed and nonprescribed opioids to opioid related deaths: population-based cohort study in Ontario, Canada. BM7 2018;362:k3207.

12. Gandhi S, Chiu M, Lam K, et al. Mental health service use among children and youth in Ontario: population-based trends over time. Can 7 Psychiatry 2016;61:119-24.

13. Injection drug use. Ontario: Canadian Research Initiative in Substance Misuse; 2017. Available: http://crismontario.ca/related-resources/drug-use-in-ontario/ injection-drug-use (accessed 2020 Jan. 17).

14. Ratnasingham S, Cairney J, Manson H, et al. The burden of mental illness and addiction in Ontario. Can $\mathcal{F}$ Psychiatry 2013;58:529-37.

15. Ratnasingham S, Cairney J, Rehm J, et al. Opening eyes, opening minds: the Ontario burden of mental illness and addictions report. Toronto: Public Health Ontario; 2012.

16. Glazier RH, Rayner J, Kopp A. Examining Community Health Centres according to geography and priority populations served, 2011/12 to 2012/13: an ICES chartbook. Toronto: ICES; 2015. Available: https://www.ices.on.ca/ /media/ Files/Atlases-Reports/2015/Examining-Community-Health-Centres/Glazier-et -al-2015-CHC-Chartbook-v2015-11-02-final2_ktl2_AY.ashx (accessed 2020 Jan. 17).

17. Gershon AS, Wang C, Guan J, et al. Identifying patients with physiciandiagnosed asthma in health administrative databases. Can Respir 7 2009;16: $183-8$.

18. Gershon AS, Wang C, Guan J, et al. Identifying individuals with physician diagnosed COPD in health administrative databases. COPD 2009;6:388-94.

19. Hux JE, Ivis F, Flintoft V, et al. Diabetes in Ontario: determination of prevalence and incidence using a validated administrative data algorithm. Diabetes Care 2002;25:512-6.

20. Tu K, Campbell NR, Chen ZL, et al. Accuracy of administrative databases in identifying patients with hypertension. Open Med 2007;1:e18-26.

21. Widdifield J, Bernatsky S, Paterson JM, et al. Accuracy of Canadian health administrative databases in identifying patients with rheumatoid arthritis: a validation study using the medical records of rheumatologists. Artbritis Care Res (Hoboken) 2013;65:1582-91.

22. Benchimol EI, Guttmann A, Mack DR, et al. Validation of international algorithms to identify adults with inflammatory bowel disease in health administrative data from Ontario, Canada. 7 Clin Epidemiol 2014;67:887-96.

23. Antoniou T, Zagorski B, Loutfy MR, et al. Validation of case-finding algorithms derived from administrative data for identifying adults living with human immunodeficiency virus infection. PLoS One 2011;6:e21748.

24. Matheson FI, van Ingen T. 2016 Ontario Marginalization Index: user guide. Toronto: St. Michael's Hospital/Public Health Ontario; 2018. Available: https://www.publichealthontario.ca/en/eRepository/userguide-on-marg.pdf (accessed 2020 Jan. 16).

25. Matheson FI, van Ingen T. 2016 Ontario Marginalization Index: frequently asked questions (FAQs). Toronto: St. Michael's Hospital/Public Health Ontario; 2018. Available: https://www.publichealthontario.ca/-/media/documents/faqs -on-marg.pdf?la=en (accessed 2020 Jan. 16)

26. Green ME, Jones CR, Walker JD, et al. First Nations and diabetes in Ontario. Toronto: ICES; 2019.

27. Brien S, Grenier L, Kapral M, et al. Taking stock: a report on the quality of mental health and addictions services in Ontario. An HQO/ICES report. Toronto: Health Quality Ontario and Institute for Clinical Evaluative Sciences; 2015. Available: http://www.hqontario.ca/portals/0/Documents/pr/ theme-report-taking-stock-en.pdf (accessed 2020 Jan. 17).

28. Pampalon R, Raymond G. A deprivation index for health and welfare planning in Quebec. Chronic Dis Can 2000;21:104-13.

29. Jaworsky D, Gadermann A, Duhoux A, et al. Residential stability reduces unmet health care needs and emergency department utilization among a cohort of homeless and vulnerably housed persons in Canada. 7 Urban Health 2016;93:666-81.

30. Brown RT, Miao Y, Mitchell SL, et al. Health outcomes of obtaining housing among older homeless adults. Am 7 Public Health 2015;105:1482-8.

31. Harris M, Gadermann A, Norena M, et al. Residential moves and its association with substance use, healthcare needs, and acute care use among home- less and vulnerably housed persons in Canada. Int 7 Public Health 2019;64: 399-409.

32. Zhang L, Norena M, Gadermann A, et al. Concurrent disorders and health care utilization among homeless and vulnerably housed persons in Canada. $\mathcal{F}$ Dual Diagn 2018;14:21-31.

33. Khandor E, Mason K, Chambers C, et al. Access to primary health care among homeless adults in Toronto, Canada: results from the Street Health Survey. Open Med 2011;5:e94-103.

34. Social determinants of health and health inequalities. Ottawa: Government of Canada; 2018. Available: https://www.canada.ca/en/public-health/services/ health-promotion/population-health/what-determines-health.html (accessed 2020 Jan. 17).

Affiliations: Arthur Labatt Family School of Nursing (Booth), Western University; ICES Western (Richard, Li, Shariff), London, Ont.; Alliance for Healthier Communities (Rayner), Toronto, Ont.

Contributions: Richard Booth and Jennifer Rayner conceived and led the study and drafted the manuscript. Lucie Richard, Lihua Li and Salimah Shariff interpreted the data and revised the manuscript critically for important intellectual content. All of the authors contributed to the study design and data analysis, approved the final version to be published and agreed to be accountable for all aspects of the work.

Funding: This study was supported by the ICES Western site. ICES is funded by an annual grant from the Ontario Ministry of Health and LongTerm Care (MOHLTC). Core funding for ICES Western is provided by the Academic Medical Organization of Southwestern Ontario, the Schulich School of Medicine and Dentistry, Western University and the Lawson Health Research Institute. This study was also supported through funding provided to Richard Booth by the Faculty of Health Sciences, Western University; through Lawson Health Research Institute Internal Research Fund grant F0598 to Richard Booth; through funding provided to Richard Booth and Jennifer Rayner by the Ontario Trillium Foundation; and through an Early Researcher Award (2017-2022) to Richard Booth from the Ontario Ministry of Research, Innovation and Science.

Data sharing: The data set from this study is held securely in coded form at ICES. Although data-sharing agreements prohibit ICES from making the data set publicly available, access can be granted to those who meet prespecified criteria for confidential access, available at www.ices.on.ca/ DAS. The full data set creation plan and underlying analytic code are available from the authors on request, with the understanding that the programs may rely on coding templates or macros that are unique to ICES and are therefore inaccessible or may require modification.

Acknowledgements: The authors thank the peer reviewers and editor for their helpful and constructive comments.

Disclaimer: This study was supported by ICES, which is funded by an annual grant from the Ontario Ministry of Health and Long-Term Care (MOHLTC). The opinions, results and conclusions reported in this article are those of the authors and are independent from the funding sources. No endorsement by ICES, the Ontario MOHLTC, the Academic Medical Organization of Southwestern Ontario, the Schulich School of Medicine and Dentistry or the Lawson Health Research Institute is intended or should be inferred. Parts of this material are based on data or information compiled and provided by the Canadian Institute for Health Information (CIHI). However, the analyses, conclusions, opinions and statements expressed in the material are those of the authors and not necessarily those of CIHI. Information in the Immigration, Refugees and Citizenship Canada Permanent Residents data set was provided by Immigration, Refugees and Citizenship Canada.

Supplemental information: For reviewer comments and the original submission of this manuscript, please see www.cmajopen.ca/content/8/2/ E391/suppl/DC1. 